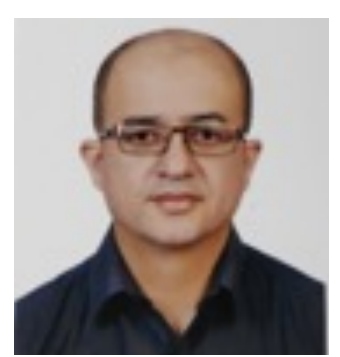

Binod Karki

\title{
It's Time to Wake Up From Our Slumber
}

"A doctor is a student till his death, when he fails to be a student, the doctor dies."

- Sir William Osler

The quote from this famous physician of eighteenth century holds true in the medical fraternity even today. The continuum of learning has never become so important than in the present era where every milestone you achieve in your career will eventually build your road ahead. The concept of Continuous Professional Development (CPD) recently made compulsory by our Nepal Medical Council (NMC) has surely stirred the medical community to some extent. Once a doctor, always a doctor, may no longer hold true if you are not practising as per the current norms and ethics and if you do not sharpen and update your skills adequately. One has to make sure that he acquires the set of skills in both compulsory fields such as basic life support, medical ethics, communication skills as well as keep oneself updated in own's specialised field of day to day practice.

The research should always be the part and parcel of such teaching learning activities. Research generates new ideas, findings and consolidates our previous beliefs or sometimes refutes the long held traditional claims and provides new insight into it. This is also dynamic and continuous in nature. Hence, the CPD should try to accredit not only the hours spent in workshops, seminars and conferences but also the research activities one has participated. The points of accreditation should be given to the articles published in a journal. This will certainly aid to the zeal and zest on part of the author to write more.

There is usually a pulsating phase of writing in most of the clinicians followed by long calmness. This pulse is usually driven to fulfil the requirements laid down by the university to uplift oneself in the academic position. What we need is an additional impetus that pierces this monotony in author's publication career and prepares him or her for the next publication. The sensitising workshop should now be even more regular and frequent in order to arouse our pen-warriors from their slumber. The art of writing needs to be inculcated right from the medical school so that it becomes a day to day habit and not just an academic obligation.

Dr Binod Karki

Associate Professor

Department of Medicine, Nepalese Army Institute of Health Sciences

Managing Editor, MJSBH

DOI: http://dx.doi.org/10.3126/mjsbh.v18i2.24443

Submitted on: 2019-03-20

Accepted on: 2019-05-15 